\title{
Commentary \\ Understanding the cognitive consequences of critical illness through experimental animal models
}

\author{
Max L Gunther ${ }^{1}$ and Brett English ${ }^{2}$
}

\author{
${ }^{1}$ Department of Radiological Sciences, Center for Health Services Research, Vanderbilt University Medical Center, Vanderbilt Institute of Imaging \\ Sciences, Nashville, TN 37232-8300, USA \\ ${ }^{2}$ Department of Pharmacology, Center for Molecular Neuroscience, 46521 st Ave South, 7150 MRB III, Nashville, TN. 37232-8548, USA
}

Corresponding author: Max L Gunther, max.gunther@venderbilt.edu

Published: 8 January 2009

This article is online at http://ccforum.com/content/13/1/104

(c) 2009 BioMed Central Ltd

See related research by Tuon et al., http://ccforum.com/content/12/5/R133
Critical Care 2009, 13:104 (doi:10.1186/cc7126)

\begin{abstract}
Tuon and colleagues have developed an animal model to examine the impact of sepsis on memory in rats. They report important data that expand the understanding of the cognitive consequences of critical illness. Future research should follow this path of inquiry and extend animal models beyond aversive conditioning to include recently developed paradigms that will permit assessment of complex and cognitive processes, such as attention, episodic memory and orientation to time and place. This has the potential to greatly increase the putative understanding of the homologous neurocognitive dysfunctions acquired during critical illness.
\end{abstract}

Major progress has been made over the past 20 years in the understanding of the cognitive consequences of critical illness. In order to expand the knowledge how disease states such as sepsis have a causal impact on the central nervous system and cognition, experimental animal models are certainly required. In a previous issue of Critical Care, Tuon and colleagues [1] reported a study in which they developed such a model in order to simulate the cognitive and behavioral effects of septic illness on memory functioning. They further provide evidence that this memory impairment can be attenuated by the administration adrenergic agents, which suggests that this mnemonic pathway may be mediated by adrenoceptors.

The methodology employed by Tuon and colleagues [1] has been used in behavioral neuroscience and comparative psychology since the inception of classical conditioning $[2,3]$. It is a well validated methodology that elicits a clear link between stimulus encoding and behavioral output. Other recent research has provided important insights into the nature of aversive memory formation. As the understanding of memory and other cognitive processes has expanded, so too have the ties between these cognitive functions and the underlying anatomy and physiology supporting these abilities. Elegant studies have revealed that memory is a complex construct indeed. Memory is a multifaceted ability that is supported by disparate and distinct circuits in the brain, so much so that ablating structures in one mnemonic pathway may have little or no effect on the functioning of another mnemonic ability. In the classic neuropsychological evaluation of patient 'HM', even with profound anterograde amnesia that developed after removal of a major section of the medial temporal lobe, he was still able to form classically conditioned memories, specifically to aversive events $[4,5]$.

In recent years several methodologies have been developed that extend the ability to address questions regarding complex cognitive processes in animal models. For example, Jonathan Crystal at the University of Georgia has demonstrated that it is possible to test not only episodic memory in animals but also attention and orientation to time and place $[6,7]$. Although each of these abilities involves a component of memory, these cognitive faculties differ in important ways from aversive classical conditioning. Not only do these mnemonic processes rely on fundamentally different neurological substrates, but they are also homologous to the memory and attentional deficits that are observed in survivors of critical illness. By incorporating paradigms such as those developed by Crystal and colleagues, future animal models have the potential to answer important questions regarding the nature of higher level cognitive deficits experienced by patients who survive critical illness in the intensive care unit (ICU). It may then be possible to begin to trace specific circuits related to ICU-acquired neurocognitive injury. This could lead to an improved understanding of the sometimes subtle nature of attentional, declarative, and executive dysfunction observed in patients after critical illness. Increasingly sophisticated animal

$\mathrm{ICU}=$ intensive care unit. 
models of higher level cognition and behavior are being developed. The hope is that these may help bridge the gap between bench research and bedside care. Experimental investigations that incorporate the ability to assess subtle changes in animal cognition offer great promise for advancing our understanding ICU acquired long-term cognitive impairment.

\section{Competing interests}

The author declares that they have no competing interests.

\section{References}

1. Tuon L, Comim CM, Petronilho F, Barichello T, Izquierdo I, Quevedo J, Dal-Pizzol F: Memory-enhancing treatments reverse the impairment of inhibitory avoidance retention in sepsis-surviving rats. Crit Care 2008, 12:R133

2. Schafe GE, Nader K, Blair HT, LeDoux JE: Memory consolidation of Pavlovian fear conditioning: a cellular and molecular perspective. Trends Neurosci 2001, 24:540-546.

3. Wilensky AE, Schafe GE, LeDoux JE: The amygdala modulates memory consolidation of fear-motivated inhibitory aviodance learning but not classical fear conditioning. J Neurosci 2000, 20:7059-7066.

4. Corkin S: What's new with the amnesic patient H.M.? Nat Rev Neurosci 2002, 3:153-160.

5. LeDoux J: The Emotional Brain. New York: Simon \& Schuster; 1996.

6. Babb SJ, Crystal JD: Discrimination of what, when, and where: Implications for episodic-like memory in rats. Learning Motivation 2005, 36:177-189.

7. Crystal JD, Maxwell KW, Hohmann AG: Cannabinoid modulation of sensitivity to time. Behav Brain Res 2003, 144:57-66. 